\title{
SUPPLY CHAIN SOFTWARE: CUSTOMER DECISION FRAMEWORK AND GLOBAL CUSTOMER PERSPECTIVE ON SOFTWARE UPGRADES AND INTEGRATION
}

\author{
Ganesh Vaidyanathan, Indiana University South Bend, gvaidyan@iusb.edu \\ Asghar Sabbaghi, Indiana University South Bend, sabbaghi@iusb.edu
}

\begin{abstract}
This study focuses on identifying the key elements that managers consider when making the decision to upgrade and integrate supply chain management system that are already in use. A survey of information systems managers is used to evaluate the proposed framework and the results of the survey suggests that managers use certain key elements when deciding on upgrading and integrating supply chain management systems. The majority of respondents, approximately $80 \%$, perceive Software Quality and Customer Services as very important factors when making the integration and upgrading decision while the remaining respondents believe that these two factors are somewhat important during the decision making process
\end{abstract}

Keywords: Supply Chain, Software, Integration, Upgrade, Framework

\section{INTRODUCTION}

In recent years, supply chain management (SCM) has received great attention in an intensified global market due to its potential contribution in reducing and eliminating trade barriers, in effective and efficient outsourcing, in creating new forms of inter-organizations, and mainly as an information technology enabler. Many managers globally have been realizing that actions taken by one member of the supply chain can influence the profitability and survival of all others in the chain (Lejeune and Yakova, 2005). The effectiveness of this supply chain depends on order fulfillment efficiency among other factors (Ricker and Kalakota, 1999). A well coordinated and an integrated supply chain management solution is needed to help manage efficient and effective flow of materials, information, and funds across the entire supply chain, from suppliers to component producers to final assemblers to distributors, and ultimately to the consumer (Ellram and Cooper 1990; Anderson and Narus 1990; Mentzer et al., 2001).
The SCM software market has numerous players, and many of them are tied to specific industries, particularly as deep knowledge of an industry and its partner networks is a key factor in the creation and support of SCM software (Morgan, 2006). Some of the top SCM solution providers are SAP, Oracle, Infor, i2 Technologies, and Manhattan Associates. These software applications must run continuously and without interruption, and yet also must be changed to fix bugs or upgrade functionality (Hicks and Nettles, 2005). The software needs to have a seamless upgrade path so that the release of new or changed features does not compromise existing integration or functionality (Fox et al., 2000). Since none of them have a complete single package for each component of supply chain management, SCM integration and periodical upgrading becomes necessary and important for businesses to achieve supply chain excellence. When deciding whether integration or upgrading is needed, what are the key elements do managers consider? Moreover, when choosing a SCM solution for SCM integration or upgrading, how do managers decide which solution fits their business the best? In the current literature, far less attention has been devoted to the post implementation activities of maintenance and upgrades (Brehm et al., 2001).

This study focuses on identifying the key elements managers consider when making the decision to upgrade and integrate supply chain management systems that are already in use. A customer decision framework for upgrading of SCM software is much needed and we present such a framework. A survey of information systems managers is used to evaluate the customer decision framework on SCM systems integration and upgrading.

The structure of this study is as follows. In the next section, we discuss the details of SCM system integration and upgrades. In the following section, we illustrate the customer 
perspectives on integration and upgrades. We present a customer decision framework in the next section. A research methodology and the results of a survey of information systems managers used to evaluate the framework are presented in the following sections. The last section includes the conclusion, limitations, and future work.

\section{SCM SYSTEM UPGRADES}

Business managers evaluate SCM solutions when making integration or upgrading decision from different perspectives. In particular, organizations typically upgrade to a new system in order to realize the benefits of substantial new functionality (Ng, 2001). Ng (2001) has analyzed maintenance data collected from an organization in the process of upgrading its ERP and SAP R/3 system to examine a decision framework for aiding an ERP user-organization in deciding if and when it should upgrade their ERP to a new version and has addressed the following questions from the ERP user-organization perspective: (1) the fundamental factors driving ERP maintenance and decision, (2) the upgrade decisions. Ng (2001) observed that the factors surrounding ERP maintenance and upgrade are found to be different from those inhouse software maintenance in three areas: (1) to realize increased benefits from the system, (2) to incorporate new functionality, and (3) to associate with less legal change patch maintenance distributed by the ERP vendors, thereby reducing the efforts associated with incorporating these patches and has concluded that existing in-house software and hardware replacement models are not sufficient for an ERP model.

\section{CUSTOMER DECISION FRAMEWORK}

To better understand SCM integration and upgrading issues, we propose a customer decision framework for integrating and upgrading software systems as shown in Figure 1. The framework consists of eight major elements affecting integration and upgrade decisions. Each element represents an issue facing the business when making the decision. In this section, we briefly describe the basic content for each of these elements in the framework.

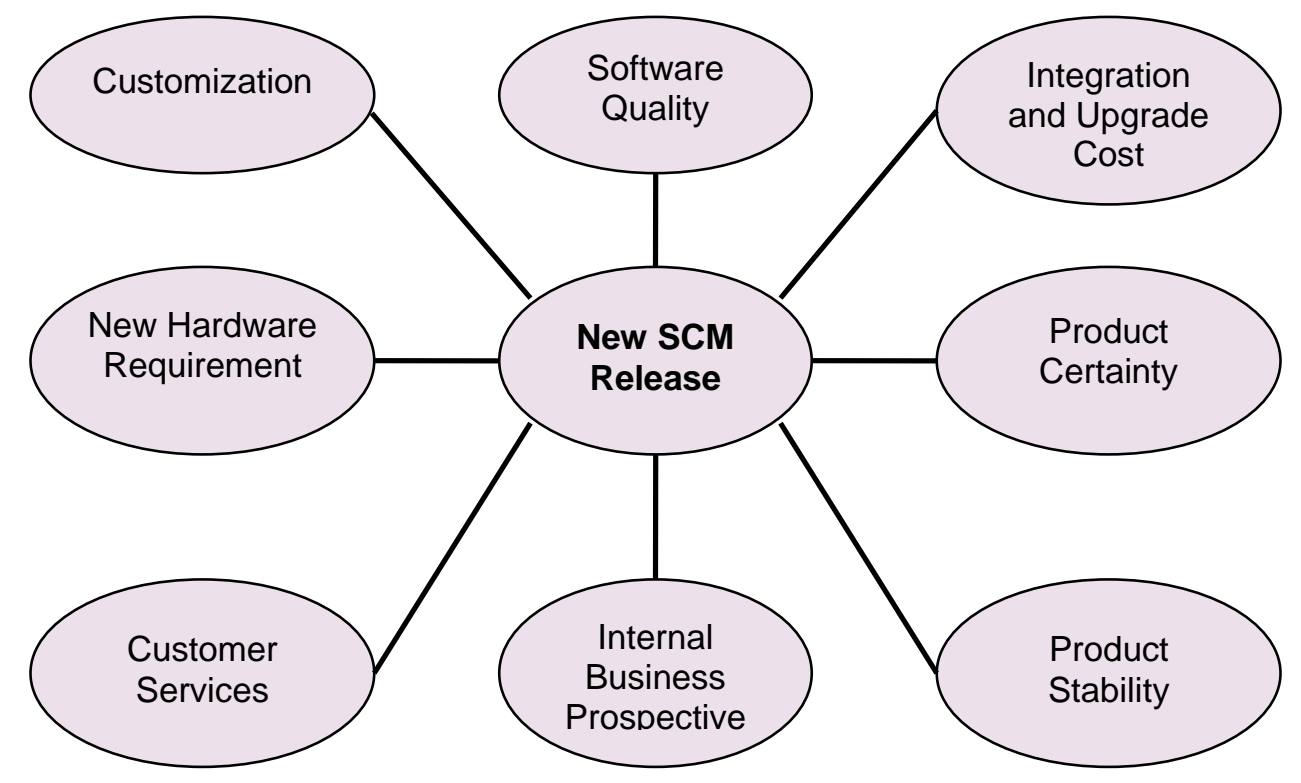

\section{Figure 1: Customer Decision Framework for Integration and Upgrading of SCM software systems}

difference of these factors from those for inhouse software, and (3) the performance of existing software and hardware replacement models when making the ERP maintenance and
Software Quality pertains to both functional and technical aspects on the solution. The solution not only needs to perform the way supposed to 
help increase the supply chain efficiency, but also needs to be able to support the desirable number of concurrent users. In addition, acceptable performance of the software is also identified as the quality of software.

Cost of SCM Integration and Upgrading should be considered as one of the most important factors. Cost of the solution package and cost of the services provided by SCM vendors fall into this category, as does the cost for in-house resources or materials needed for the integration or upgrading, etc. The upgrade cost, similar to the initial implementation, consists of software cost, hardware cost, user training, consultancy fees, and the upgrade implementation. A new version which has more functionality, flexibility, and extensibility will generally cost more to upgrade According to some estimates, some software for instance, SAP R/3 upgrade cost users 25-30 percent of initial investment (Songini, 2000). Financial Perspective examines the net present value (NPV) or the return on Investments (ROI) on the integration and upgrading decision. This perspective is would include the type and period of returns. Cost reduction is considered as one of the financial perspectives during the decision making process. The business case for the large-scale use of commercial-of-the -shelf (COTS) components in a software development project must be supported by sound economic arguments (Erdogmus and Vandergraaf, 1999).

Product Certainty encompasses all the defined "facts" of the SCM solution - the current functionalities supported, the number of concurrent users supported, to name a few. In particular, standardization of the system play a major role in their data communication facilities and personnel training but also improve their business processes and facilitate collaboration between partners. This can be supported by the use of an integrated ERP. According to Vice President of Supply Chain at NIBCO, "Having a standardized system across our network of plants helps us do many more things remotely than before. Further, it reduces personnel training expenses and helps us leverage expertise across our plants. Personnel can move from one factory to another and be ramped up very quickly-this makes our associates even more agile and flexible” (Brown et al., 2003). In addition, the software performance defined by vendors also belongs to this category, such as time needed to process 100,000 packages through the warehouse.

Product Stability is concerned attributes that consider the future and robustness of the product, the financial viability and stability of the vendor and the overall stability of the industry related to the product's vertical market. This attribute is important because decision makers want to ensure their investment can be supported throughout the intended life of the product (Seibel, 2005). For many software vendors, the competition for rushing a new version to market is more important than delivering a high level of software reliability, usability and other qualities (Clapp and Taub, 1998).

Internal Business Perspectives deals with business philosophy and issues, such as the time required for the integration and upgrading and potential business risks. If a SCM solution comparatively takes too long to integrate or upgrade for a firm, it could pose great business risks and might simply not be a good fit. The Vice President of Supply Chain at NIBCO stated that "we took the SAP implementation as an opportunity to redefine our supply chain business processes. The implementation was trigger to make it happen. It also helped us define and communicate our supply chain philosophy" (Brown et al., 2003).

Customer Services is to be considered the most important factors by many business managers and SCM professionals. It examines not only the service provided during the integration or upgrading, but also the ones provided by vendors post-installation. This can be not only tried out through business's own experience, but also examined through industry reputations, vendor company culture, etc. Sahin and Zahedi (2001) have examined the maintenance issues faced by the vendors. In their view, a software vendor has to decide if and when these patches or upgrades should be introduced to the user-organizations. Since these upgrades could be costly to the vendor and at the same time delaying them could degrade customer satisfaction and affect the revenues. They propose that a software vendor may make software upgrade decisions in response to the current level of customer satisfaction, which directly determines the revenues of the vendor. For instance, according to Brown et al. (2003), before the go-live in NIBCO, management developed a new metric to better capture and monitors its ability to satisfy 
its customers. "Internally called Big 6, NIBCO developed a perfect order metric to capture the percentage of orders that were perfectly fulfilled. The metric is calculated by multiplying six elements, which include order accuracy, product availability, and order-to-ship timeliness." According to the Director of Supply Chain System at NIBCO, "you do not compete in our market any more with product and price; you've got to compete with service ...the Big 6 metric became a large part of our culture" (Brown et al., 2003).

New Hardware Requirement is listed as a separate element because not all integration or upgrading requires this additional investment. This area deals with all necessary or recommended new hardware for the integration or upgrading, such as servers, RFID devices, terminals/PCs, etc. Some midsize to smaller firms who would like to minimize their total investment in project might take this element into consideration. For example CIO at NIBCO argued that they made a strategic decision to stay relatively current on both hardware and software. They upgraded SAP every 18 to 24 months (Brown et al., 2003).

Customization presents the configuration flexibility provided by the solution. As indicated by Granter research report, customization ability has become one of the latest business drivers in the SCM market. This elements addresses the customization as simple as changing the security setting for members of the firm, to as complicate as total business process re-engineering by redesign the entire business work flow. For instance, NIBCO re-engineered its supply chain process with the initial implementation of SAP $\mathrm{R} / 3$, and replaced the long-established forecastpush approach with a demand-pull approach in supplying product to customers (Brown et al 2003). This initiative significantly affected all aspects of NIBCO's supply chain, cutting across customer service, the distribution system, manufacturing operations, and procurement. This new system is notable due to: (1) customization and its reliance on actual customer orders vs. demand forecast as the driver for day-today replenishment, and (2) the direction of triggers for the movement of product from the marketplace rather than from the manufacturer.

\section{INITIAL SURVEY RESULTS}

In order to evaluate the eight factors of the customer decision framework, a survey with questions that evaluate the importance of each element was conducted. The respondents include professionals who help with the evaluation of current supply chain technology usage and the level of integration of business

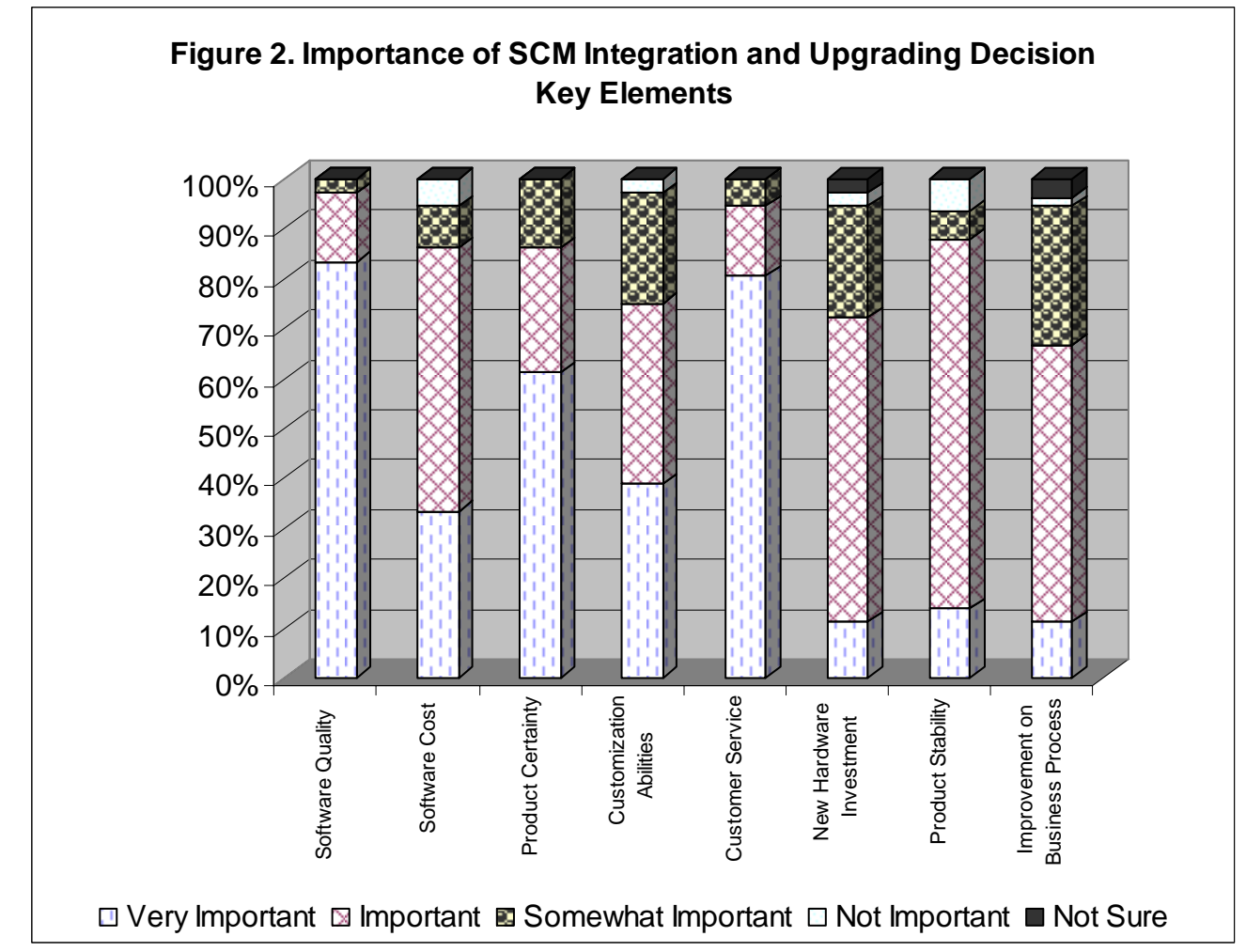


applications from various manufacturing firms across the country. The solicitation was primarily through mail and email based on membership directories, mailing lists, and attendance at professional meetings. Out of 300 individuals contacted, 151 participated in the study yielding a response rate of about $50 \%$. Each participant completed one survey, and the survey captured the perceptions of their SCM software upgrade experience.

\section{DISCUSSION}

Figure 2 illustrates the overall important factors that make up the integration and upgrading decisions by managers. The aggregate graph is used in this paper to understand the overall effects of the decision factors. Based on Figure 2 , the order in which managers perceive the importance of integration and upgrading are as follows:
1. Software Quality
2. Customer Service
3. Product Certainty
4. Customization Abilities
5. Software Cost
6. Product Stability
7. New Hardware Requirement
8. Improvement on Business Process.

Based on the results, the majority of respondents, approximately $80 \%$ perceive software quality as the most important factor when making the integration and upgrading decision while the remaining respondents believe that this factor is somewhat important during the decision making process. These observations indicate that the quality of the SCM solution provided is definitely considered as the key element by business managers.

Achieving quality software is an important and somewhat elusive goal and software quality includes many attributes such as functionality, the appearance of user interface, reliability, testability, portability, usability, extensibility, and maintainability (Yang, 2001). Ravichandran and Rai (2000) also agree that quality improvement in systems development ranks high among the priorities of information systems managers today. Harter et al., (2000) acknowledge that higher quality in turn leads to reduced cycle time and development effort in the software products. Software vendors are therefore attempting to build quality into the product by avoiding defects in the first place, instead of removing the defects in the product through rigorous testing (Krishnan et al., 2000). International standards for quality such as ISO9000-3 and the Capability Maturity Model (CMM) of the Software Engineering Institute have been adopted by many software organizations over the past few years.

The second important factor is customer services. About $76 \%$ of the managers perceive that customer services is very important while more than $10 \%$ feel that this is an important factor. Karimi (2001) acknowledges that customer service is a top priority for many business and information technology executives. In addition, the survey has shown encouraging numbers for the importance of upgrade cost, certainty of the software as well as ROI and cost reduction with more than $80 \%$ of respondents rate them with an "Important" level or above. It has also justified that these three factors in the hypotheses are indeed the key elements when managers making the SCM integration and upgrading decision. Based on the survey results, elements such as customization abilities, additional hardware requirements and business process improvement seem to be weighted less by the respondents. More than $90 \%$ of the respondents still believe these three factors are at least somewhat important when making the integration and upgrading decision. In order to obtain the next level of supply chain collaboration, managers will still need to consider further SCM integration or upgrading their current systems in the near future.

\section{CONCLUSION, LIMITATIONS, AND FUTURE WORK}

Traditionally, SCM implementations are built upon a linear, standard, and relatively stable view of the supply chain (Kov and Paganelli, 2003). SCM solutions in this approach are product suites including several independent tools, each designed to optimize a single link in a predefined sequence (Kov and Paganelli, 2003). Our study has proposed a framework to examine integration and upgrading decisions of mangers. This is an exploratory framework and survey. We are further expanding this study to test the framework empirically. We have covered eight key elements often considered by business managers when making the supply chain management integration or upgrading decision. Businesses operate in global environments, deal with multiple suppliers and customers, are 
required to manage inventories in new and innovative ways, and are faced with possible channel restructuring. This study will open many more research yet to be conducted to understand the customer decision factors for upgrading and integration of software.

\section{REFERENCES}

1. Anderson, E., Narus, J.A. (1990). A model of distributor firm and manufacturer firm working relationships. Journal of Marketing, 54 (Jan), 42-58.

2. Brehm, L., Heinzl, A., Markus, M.L. (2001). Tailoring ERP systems: A spectrum of choices and their implications. Proceedings of the 34th Hawaii International Conference on System Sciences, Maui, Hawaii, 8, 8017-8025.

3. Brown, C., Tatikonda, M., Vessey, I. (2003). NIBCO: My SAP Supply Chain Management. (Available at http://www11. sap.com/americas/solutions/business-suite/ scm/pdf/nibco_full_report.pdf; accessed on February 5, 2006).

4. Clapp, J.A. Taub, A.E. (1998). A Management Guide to Software Maintenance in COTS-based Systems. Mitre Center for Air Force C2 Systems: Bedford, MA.

5. Ellram, L.M. Cooper, M.C. (1990). Supply chain management, partnerships, and the shipper-third-party relationship. The International Journal of Logistics Management, 1 (2), 1-10.

6. Erdogmus, H, Vandergraaf, J. (1999). Quantitative approaches for assessing the value of COTS-centric development. Sixth International Symposium on Software Metrics, November 4-6, Boca Raton, FL.

7. Fox, M.S., Barbuceanu, M., Teigen, R. (2000). Agent-oriented supply-chain management. The International Journal of Flexible Manufacturing Systems, 12, 165188.

8. Harter, D.E., Krishnan, M.S., Slaughter, S.A. (2000). Effects of process maturity on quality, cycle time, and effort in software product development. Management Science, 46 (4), 451-466.

9. Hicks, M., Nettles, S. (2005). Dynamic software updating. ACM Transactions on Programming Languages and Systems, 27 (6), 1049 - 1096.

10. Karimi, J. (2001). Impact of Information Technology Management Practices on
Customer Service. Journal of Management Information Systems, 17 (4), 125-158.

11. Krishnan, M.S, Kriebel, C.H., Kekre, S., Mukhopadhyay, T. (2000). An empirical analysis of productivity and quality in software products. Management Science, 46 (6), 745-759.

12. Kov, G.L., Paganelli, P. (2003). A planning and management infrastructure for large, complex, distributed projects-beyond ERP and SCM. Computers in Industry, 51, 165-183.

13. Lejeune, M.A., Yakova, N. (2005). On characterizing the 4 C's in supply chain management. Journal of Operations Management, 23 (5), 81-100.

14. Mentzer, J.T., DeWitt, W., Keebler, J.S., Min, S., Nix, N.W., Smith, C.D., Zacharia, Z.G. (2001). Defining supply chain management. Journal of Business Logistics, 22 (2),1-25.

15. Morgan, T.P. (2006). Supply chain software sales still growing, according to AMR. IT Jungle, 15 (37).

16. Ng, C.S.P. (2001). A decision framework for enterprise resource planning maintenance and upgrade: A client perspective. Journal of Software Maintenance and Evolution: Research and Practice, 13 (6), 431-468.

17. Ravichandran, T., Rai, A. (2000). Quality Management in Systems Development: An Organizational System Perspective. MIS Quarterly, 24 (3), 381-415.

18. Ricker, F.R., Kalakota, R. (1999). Order fulfillment: The hidden key to e-commerce success. Supply Chain Management Review, 11 (3), 60-70.

19. Sahin, I, Zahedi, F. (2001). Control limit policies for warranty, maintenance and upgrade of software systems. IIE Transactions, 33(9), $729-745$.

20. Seibel, J.S. (2005). An attribute proposal for same vendor, version to-version COTS upgrade decisions, 2005 Joint Symposium, Lockheed Martin Engineering Process Improvement Center, 1-15 (available at http://www.cotsresearch.com; accessed on February 5, 2006).

21. Songini, M.L. (2000). Users vent frustration over Oracle CRM/ERP upgrades, Computerworld, 34 (44), 105.

22. Yang, Y.H. (2001). Software quality management and ISO 9000 implementation. Industrial Management \& Data System, 101 (7), 329-338. 